\title{
Metabolic effects of discontinuing growth hormone treatment
}

\author{
F J Cowan, W D Evans, J W Gregory
}

\begin{abstract}
Aims-To evaluate the effects of discontinuing growth hormone (GH) treatment on energy expenditure and body composition, which might help predict those most likely to benefit from early reintroduction of GH treatment in young adult life.

Methods-Body composition was calculated from skinfold thicknesses and dual energy $x$ ray absorptometry (DXA). Resting metabolic rate (RMR) and whole body bone mineral content (BMC) were also measured. Measurements were made before stopping treatment, at discontinuation of GH treatment, and two weeks, six months, and one year later in 11 adolescents with growth hormone deficiency (GHD) and five adolescents without GHD who were treated with GH. Measurements were compared with 10 healthy controls, in whom measurements were repeated one year later.
\end{abstract}

Results-During the nine months before discontinuation of $\mathrm{GH}$ there were no changes in body composition, RMR, or BMC of patients with GHD, nor differences when compared with controls. RMR was reduced by $11.3 \mathrm{~kJ} / \mathrm{kg}$ fat free mass two weeks after stopping GH in GHD patients and remained suppressed thereafter compared with controls. Percentage body fat increased by $4.3 \%$ /year in patients with GHD after discontinuing GH, whereas no changes were noted in control or non-GHD patients at one year. The patients experiencing the greatest reductions in $R M R / k g$ fat free mass at six months showed the largest increases in body fat at one year. No change in BMC was noted in patients one year after stopping treatment.

Conclusion-Important metabolic changes occur early after discontinuing GH treatment. In patients whose growth is complete, these changes might be used to predict those most likely to benefit from continuation of GH treatment into adult life.

(Arch Dis Child 1999;80:517-523)

Keywords: growth hormone deficiency; body composition; resting metabolic rate; bone mineralisation

Health, University of Wales College of

Medicine, Heath Park, Cardiff CF4 4XN, UK

J W Gregory

Correspondence to:

Dr Gregory.

Accepted 22 December 1998 is associated with increased adiposity, ${ }^{1}$ adverse serum lipid profiles, ${ }^{2}$ and reduced exercise capacity. ${ }^{3}$ Lethargy, low mood and social isolation, ${ }^{4}$ reduced bone mineral density, ${ }^{5}$ and excess mortality, partly the result of increased cardiovascular deaths, ${ }^{6}$ have also been reported. GH treatment is known to have an anabolic effect in both children and adults, increasing nitrogen retention within days of starting treatment. ${ }^{7}$ Increased nitrogen retention reflects increased protein synthesis and fat free mass, which in turn are associated with increased energy expenditure. ${ }^{8}$ As a consequence of these early metabolic changes, growth hormone $(\mathrm{GH})$ treatment in adults with severe GH deficiency (GHD) produces improvements in exercise capacity, ${ }^{9}$ body composition, ${ }^{10}{ }^{11}$ and psychological well being, ${ }^{12}$ and is now used in the treatment of adults with severe GHD.

At present, it is unclear which individuals diagnosed as having GHD in childhood would benefit from continuing $\mathrm{GH}$ treatment into adult life. Currently, GH treatment is discontinued when patients have completed their pubertal growth spurt. Forty per cent of individuals diagnosed as having GHD in childhood no longer demonstrate GHD when re-tested as young adults. ${ }^{13}$ Therefore, it is likely that not all children treated with $\mathrm{GH}$ for previously diagnosed GHD in childhood will benefit from treatment in adult life. Important early metabolic changes have been demonstrated after the start of $\mathrm{GH}$ treatment in children. ${ }^{8}$ These include an increase in resting metabolic rate (RMR) and fat free mass and a decrease in fat mass. These early metabolic changes are correlated with longer term changes in growth. ${ }^{14}$ We hypothesised that reversal of these metabolic effects would occur on discontinuing $\mathrm{GH}$ treatment and that the magnitude of these early metabolic changes might be predictive of later changes in body composition. These changes might therefore be used to identify those individuals most likely to suffer adverse effects from discontinuation of GH treatment in early adult life and therefore those most likely to benefit from continuation of treatment.

\section{Subjects and methods} SUBJECTS

Eleven adolescent patients (seven boys) who discontinued $\mathrm{GH}$ treatment were studied. The median age was 17.0 (range, 14.5 to 18.5 ) years and 10 were postpubertal. GH secretory status before treatment with $\mathrm{GH}$ had been assessed in these patients by measuring their response to insulin induced hypoglycaemia (nine patients) and glucagon (two patients). GHD was diagnosed when the maximum serum $\mathrm{GH}$ concentration was $<20 \mathrm{mU} / \mathrm{ml}$. The median pretreatment maximum $\mathrm{GH}$ 
Table 1 Patient details

\begin{tabular}{lcll}
\hline & GHD group & Non-GHD group & Controls \\
\hline Age (years) & $17.0(14.5$ to 18.5$)$ & $16.2(14.4$ to 17.4$)$ & $16.8(16.5$ to 17.1$)$ \\
Height SDS & $-1.2(-2.7$ to 0.7$)$ & $-2.7(-2.7 \text { to }-2.2)^{\star}$ & $0.32(-1.3$ to 1.7$) \dagger$ \\
Weight SDS & $-0.7(-2.0$ to 3.7$)$ & $-1.3(-3.5$ to 0.5$)$ & $0.44(-1.1$ to 1.4$) \ddagger$ \\
BMI SDS & $0.1(-2.1$ to 3.3$)$ & $-0.1(-2.9$ to 1.2$)$ & $0.53(-1.2$ to 1.9$)$ \\
\hline
\end{tabular}

All values are median (range)

${ }^{\star} \mathrm{p}<0.005$, non-GHD (growth hormone deficient) group compared with GHD group.

$t \mathrm{p}<0.005$, controls compared with GHD and non-GHD groups.

$\neq \mathrm{p}<0.05$, controls compared with non-GHD group.

concentration was 6.2 (range, 0.2 to 16.9 ) $\mathrm{mU} /$ $\mathrm{ml}$. Seven individuals had isolated GHD and four had multiple pituitary hormone deficiencies. GH deficiency was idiopathic in three cases, associated with a craniopharyngioma in one case, and in seven resulted from treatment for malignancy (astrocytoma, acute lymphoblastic leukaemia (two patients), nonHodgkin's lymphoma, glioma, rhabdomyosarcoma, and medulloblastoma). There were no differences in the maximum GH concentrations between the individuals with isolated GHD and those with multiple pituitary hormone deficiencies. The median length of $\mathrm{GH}$ treatment was 7.5 (range, 1.7 to 11.8 ) years.

The effects of discontinuing GH treatment in patients with GHD were compared with those obtained in two other groups of adolescents: 10 healthy postpubertal controls (three boys) recruited from a local school, median age 16.8 (range, 16.5 to 17.1 ) years and five individuals (one male) who had been treated with GH but who were did not have GHD, median age 16.2 (range 14.4 to 17.4 ) years. Three of these had Turner's syndrome, one Leri-Weill syndrome, and one normal variant short stature (maximum serum GH concentration, $53.2 \mathrm{mU} / \mathrm{ml}$ during serial measurements made every 20 minutes overnight). Patients with Turner's syndrome and Leri-Weill syndrome did not undergo pretreatment GH testing but there were no clinical signs to suggest GHD and a cause for their short stature was evident. The median length of $\mathrm{GH}$ treatment was 3.2 (range, 2.0 to 7.0 ) years. Four patients were postpubertal. The three girls with Turner's syndrome all had ovarian failure and were being treated with a combination of ethinyloestradiol and norethisterone (Loestrin 20). These non-GHD patients were included to assess the effect of stopping $\mathrm{GH}$ per se, to determine whether any metabolic changes seen in the patients with GHD were indicative of continuing endocrinopathy and not simply a result of discontinuing $\mathrm{GH}$ treatment.

METHODS

In patients treated with $\mathrm{GH}$, measurements of RMR and body composition were made at a median of 9.4 (range 4 to 20) months before discontinuing $\mathrm{GH}$, at discontinuation of $\mathrm{GH}$, and two weeks, six months, and one year later. Similar measurements were made on two occasions a year apart in the healthy controls. Height was measured using a wall mounted Harpenden stadiometer (Holtain Ltd, Crymych, Dyfed, UK) and weight by a beam balance (Avery Ltd, Birmingham, UK). Body mass index was calculated from weight $(\mathrm{kg}) /$ height $(\mathrm{m})^{2}$. Measurements were expressed as standard deviation scores (SDS) using the 1990 growth standards for British children. ${ }^{15} 16$ Puberty was assessed by the method of Tanner. ${ }^{17}$

\section{Resting metabolic rate}

At each visit, RMR measurements were made under standard conditions, early in the morning in the fasted state, with the subjects resting supine in a thermoneutral environment. On each occasion, the first 10 minutes of the RMR measurements were discarded to ensure that steady state resting values were obtained. Oxygen consumption and carbon dioxide production were measured by ventilated hood indirect calorimetry (Deltatrac II MBM-200 metabolic monitor; Datex, Helsinki, Finland) and RMR was calculated using the equation of Weir. ${ }^{18}$ Because RMR is dependent on body size and the proportion of metabolically active tissue, RMR (kJ/day) has also been expressed adjusted for body size $(\mathrm{kJ} / \mathrm{kg}$ body weight/day) and for fat free mass $(\mathrm{kJ} / \mathrm{kg}$ fat free mass/day).

\section{Body composition}

Body composition was measured by skinfold thickness and dual energy $x$ ray absorptometry (DXA). Skinfold thickness measurements were made using a Holtain skinfold caliper at the triceps, biceps, subscapular, and suprailiac

Table 2 Resting metabolic rate (RMR) values

\begin{tabular}{|c|c|c|c|c|c|}
\hline$R M R(k \mathcal{F})$ & $\begin{array}{l}\text { Before stopping } \\
\text { treatment }\end{array}$ & At discontinuation & $\begin{array}{l}\text { Two weeks after stopping } \\
\text { treatment }\end{array}$ & $\begin{array}{l}\text { Six months after stopping } \\
\text { treatment }\end{array}$ & $\begin{array}{l}\text { One year after stopping } \\
\text { treatment }\end{array}$ \\
\hline \multicolumn{6}{|l|}{ RMR/day } \\
\hline GHD group & $6039(1383)$ & $6065(1353)$ & $5451(1155)^{\star}$ & $5345(838)^{\star}$ & 5507 (1339) \\
\hline Non-GHD group & $5174(442)$ & $5341(364)$ & $4943(201)$ & $5257(390)$ & $5005(517)$ \\
\hline Controls & & $6332(1036)$ & & & $6928(1346) \rrbracket$ \\
\hline \multicolumn{6}{|l|}{$\mathrm{RMR} / \mathrm{kg} /$ day } \\
\hline GHD group & $106.8(15.9)$ & $105.2(14.1)$ & $95.9(17.1)^{\star}$ & $91.7(17.9)^{\star}$ & $90.4(13.9)^{\star}$ \\
\hline Non-GHD group & $122.3(17.5)$ & $123.0(7.4) \ddagger$ & $114.1(13.1)$ & $114.7(7.4)^{\star} \dagger$ & $110.9(14.0)^{\star}+$ \\
\hline Controls & & $98.4(11.5)$ & & & 105.7 (11.9)† \\
\hline \multicolumn{6}{|l|}{$\mathrm{RMR} / \mathrm{kgFFM} /$ day } \\
\hline GHD group & $140.1(15.0)$ & $136.9(11.3)$ & $125.6(13.6)^{\star}$ & $124.3(15.8)$ * & $125.1(9.3)^{\star}$ \\
\hline Non-GHD group & $168.2(21.7) \dagger$ & $168.1(11.7) \ddagger$ & $151.4(9.7) \dagger$ & $160.2(8.8) \dagger$ & $151.9(19.6) \dagger$ \\
\hline Controls & & $140.4(11.1)$ & & & $150.8(15.7) \dagger$ \\
\hline
\end{tabular}

All values are mean $(\mathrm{SD})$

${ }^{\star} \mathrm{p}<0.01$ compared with values at discontinuation of (growth hormone) GH treatment.

$t \mathrm{p}<0.005$ compared with the GHD group.

$\ddagger \mathrm{p}<0.05$ compared with the GHD group and controls.

$\widehat{~} \mathrm{p}<0.05$ compared with values at discontinuation and compared with the GH deficient (GHD) and non-GHD group at one year

$\lceil\mathrm{p}<0.05$ compared with controls.

FFM, fat free mass. 


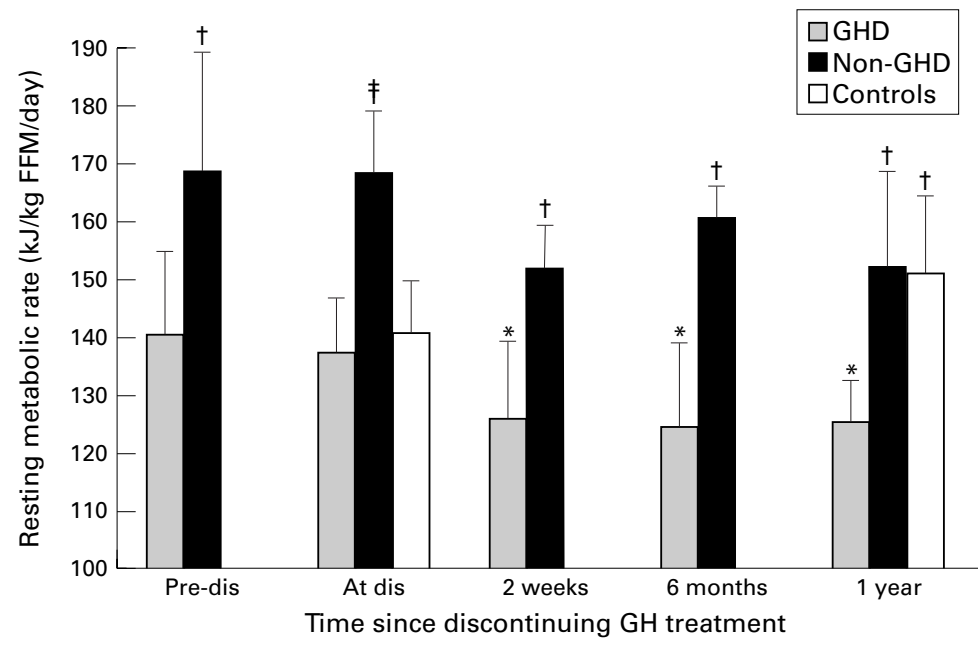

Figure 1 Mean (SD) resting metabolic rate before discontinuing (Pre-dis) GH treatment, at discontinuation (At dis) of treatment, and two weeks, six months, and one year after stopping treatment. ${ }^{\star} p<0.01$ compared with values at discontinuation of $G H$ treatment; $t p<0.005$ compared with GHD group; $\neq p<0.05$ compared with GHD group and controls.

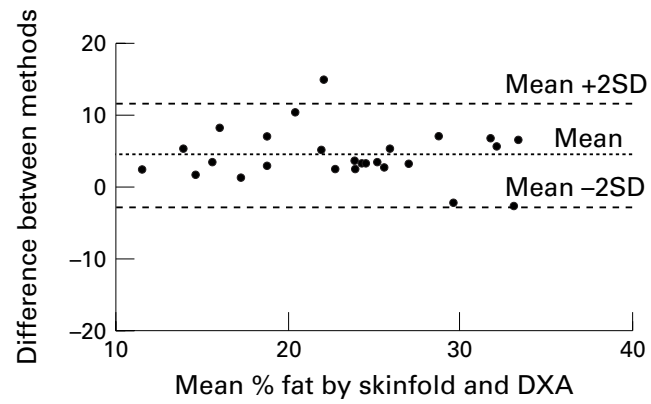

Figure 2 Agreement between skinfold thickness and DXA measurements of percentage fat. The difference between methods is the skinfold measurement minus the DXA measurement of percentage fat.

hoc multiple comparison test was applied. Agreement between the two methods of measuring body composition was assessed by the method described by Bland and Altman. ${ }^{23}$

\section{Results}

Patients with and without GHD and healthy controls were of similar age (table 1). The GHD and non-GHD patients were shorter and lighter than the controls, with the non-GHD patients being significantly shorter than those with GHD (table 1). There were no differences in body mass indices between the groups. The non-GHD group had received $\mathrm{GH}$ for a shorter median time than those with GHD but the difference was not significant.

DXA measurements of fat free mass, fat mass, and percentage fat were performed using a QDR 1000/W scanner (Hologic Inc, Waltham, Massachusetts, USA) ${ }^{21}$ DXA measurements of body composition in the healthy control individuals were only made at the initial assessment, although skinfold thickness and RMR measurements were repeated one year later.

\section{Bone mineralisation}

Whole body bone mineral content (BMC) and bone area (BA) were measured by DXA scanning using the QDR 1000/W scanner. Conventionally, bone mineral data derived from DXA have been presented as areal density, yet this fails to account for changes in BMC that result from changes in age and body size. Therefore, predictive formulae were used for BMC that provide a method for interpreting the measured BMC, which is independent of these variables. ${ }^{22}$ The measured BMC was expressed as a percentage of the predicted value (\%BMC), which allows comparison of values in subjects with a wide range of body size and age.

Our study was approved by the South Glamorgan and Newcastle local research ethics committees and informed consent was obtained from each patient.

\section{STATISTICAL ANALYSIS}

Group means were compared using independent $t$ tests. Changes within subjects were compared using paired $t$ tests. The different diagnostic groups were compared using one way analysis of variance (ANOVA). Where the $F$ ratio was significant $(p<0.05)$, Tukey's post
RESTING METABOLIC RATE

While on GH treatment there were no significant differences between RMR values for patients with GHD compared with the healthy control subjects, whereas the non-GHD group had a significantly higher RMR at discontinuation of GH treatment. There were no significant changes in RMR in the GHD group or the non-GHD group during the year before discontinuation of GH. Significant reductions in $\mathrm{RMR} / \mathrm{kg}$ fat free mass/day were seen two weeks, six months, and one year after discontinuation of $\mathrm{GH}$ treatment $(11.3,12.6$, and $11.8 \mathrm{~kJ} / \mathrm{kg}$ fat free mass/day, respectively; $\mathrm{p}<0.01$ ) only in those with GHD. In the nonGHD group, RMR/kg fat free mass/day remained significantly higher than in the GHD group on each occasion, and no significant reduction was noted over the year of the study. After one year, the healthy control subjects had a significantly increased RMR when expressed as $\mathrm{kJ} /$ day, but not when corrected for body size and composition (table 2). RMR/kg fat free mass/day was significantly lower in the patients with GHD compared with controls and non-GHD individuals one year after stopping treatment. Although RMR/kg fat free mass/day was higher in the non-GHD group while on $\mathrm{GH}$ than in controls, there was no difference between the two groups one year after discontinuing $\mathrm{GH}$ (fig 1).

Percentage fat values were consistently higher when measured by skinfold thickness than by DXA. There was a mean bias of $4.4 \%$ (limits of
BODY COMPOSITION 
Table 3 Skinfold measurements of body composition

\begin{tabular}{lllll}
\hline & $\begin{array}{c}\text { Before stopping } \\
\text { treatment }\end{array}$ & At discontinuation & $\begin{array}{l}\text { Six months after stopping } \\
\text { treatment }\end{array}$ & $\begin{array}{l}\text { One year after stopping } \\
\text { treatment }\end{array}$ \\
\hline $\begin{array}{l}\text { Fat free mass (kg) } \\
\text { GHD group }\end{array}$ & $43.7(12.2)$ & $44.7(12.5)$ & $44.0(11.8)$ & $44.5(12.9)$ \\
$\quad \begin{array}{l}\text { Non-GHD group } \\
\text { Controls }\end{array}$ & $31.2(2.3)$ & $32.8(1.9) \dagger$ & $32.9(2.4)$ & $33.1(2.0) \dagger$ \\
Fat mass (kg) & & $45.1(6.5)$ & & $46.0(7.5)$ \\
GHD group & $14.6(9.2)$ & $14.9(10.4)$ & $17.2(11.4)^{\star}$ & $18.8(13.2)^{\star}$ \\
Non-GHD group & $11.4(1.7)$ & $10.8(3.2) \dagger$ & $13.1(2.3)$ & $12.5(4.3) \dagger$ \\
Controls & & $17.8(4.9)$ & & $19.6(5.8)^{\star}$ \\
\% Body fat & & $23.7(7.2)$ & $26.7(7.8)^{\star}$ & $28.0(8.0)^{\star}$ \\
GHD group & $23.8(6.6)$ & $24.3(5.1)$ & $28.4(2.4)^{\star}$ & $26.8(6.3)$ \\
$\quad \begin{array}{l}\text { Non-GHD } \\
\text { Controls }\end{array}$ & $26.7(1.9)$ & $28.0(5.3)$ & & $29.6(6.8)$ \\
\hline
\end{tabular}

All values are mean $(\mathrm{SD})$

${ }^{\star} \mathrm{p}<0.05$ compared with value at discontinuation of growth hormone $(\mathrm{GH})$ treatment.

tp $<0.05$ compared with controls.

Table 4 Dual energy $x$ ray absorptometry measurements of body composition

\begin{tabular}{lllll}
\hline & $\begin{array}{c}\text { Before stopping } \\
\text { treatment }\end{array}$ & At discontinuation & $\begin{array}{l}\text { Six months after stopping } \\
\text { treatment }\end{array}$ & $\begin{array}{l}\text { One year after stopping } \\
\text { treatment }\end{array}$ \\
\hline $\begin{array}{l}\text { Fat free mass (kg) } \\
\text { GHD group }\end{array}$ & $44.2(14.1)$ & $45.8(13.7)$ & $48.3(12.6)$ & $44.8(15.0)$ \\
$\quad \begin{array}{l}\text { Non-GHD } \\
\text { Controls }\end{array}$ & $32.0(2.3)$ & $33.0(2.2) \ddagger$ & $33.1(2.2) \dagger$ & $33.4(2.5)$ \\
Fat mass (kg) & & $48.0(9.4)$ & & $18.7(13.6)^{\star}$ \\
GHD group & $12.0(7.3)$ & $12.2(8.5)$ & $18.6(13.2)^{\star}$ & $11.2(3.8)$ \\
Non-GHD & $9.7(1.4)$ & $9.2(2.8)$ & $11.5(2.5)$ & \\
Controls & & $13.3(4.2)$ & & $27.8(8.8)^{\star}$ \\
\% Fat & $19.9(6.9)$ & $20.0(7.6)$ & $25.9(7.7)^{\star}$ & $24.7(5.9)$ \\
GHD group & $23.2(1.4)$ & $21.5(4.6)$ & $25.6(3.0)$ & \\
$\quad$ Non-GHD group & & $21.9(6.7)$ & &
\end{tabular}

All values are mean $(\mathrm{SD})$.

${ }^{\star} \mathrm{p}<0.05$ compared with value at discontinuation of GH treatment.

$t \mathrm{p}<0.05$ compared with the GHD group.

$\neq \mathrm{p}<0.05$ compared with controls.

agreement, $11.5 \%$ to $-2.7 \%$ ) when skinfold thicknesses were compared with DXA measurements (fig 2).

When measured by skinfold thicknesses, patients with GHD had an increase in fat mass and percentage body fat at six months $(2.3 \mathrm{~kg}$ and $3.0 \%$, respectively; $p<0.05)$ and one year (3.9 $\mathrm{kg}$ and $4.3 \%$, respectively; $\mathrm{p}<0.05$ ) after stopping GH (table 3; fig 3). DXA measurements revealed even larger changes $(6.4 \mathrm{~kg}$ and $5.9 \%$, respectively, at six months and $6.5 \mathrm{~kg}$ and $7.8 \%$, respectively, at one year; all values $\mathrm{p}<0.05$ ) in the patients with GHD (table 4). Over the year, healthy control subjects also demonstrated a small mean increase in fat mass $(1.8 \mathrm{~kg})$ measured by skinfold thicknesses $(\mathrm{p}<0.05)$, although this change was not

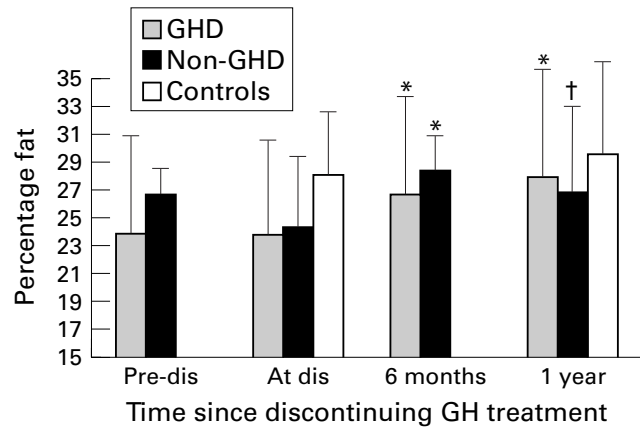

Figure 3 Mean (SD) percentage fat by skinfold thickness before discontinuing GH treatment (Pre-dis), at discontinuation (At dis), and two weeks, six months, and one year after stopping treatment. ${ }^{\star} p<0.05$, compared with values at discontinuation of $G H$ treatment; $t p<0.05$ compared with controls at one year. significant when expressed as percentage body fat. No significant changes in fat mass were demonstrated in the non-GHD patients. Percentage body fat was increased in the nonGHD group at six months, when measured by skinfold thickness $(4.1 \% ; \mathrm{p}<0.05)$ but not when measured by DXA, and at a year was no longer significantly different from the time when GH was discontinued. No significant changes in fat free mass were seen in the healthy control group or either of the patient groups.

There were significant associations between changes in RMR/kg fat free mass/day and subsequent changes in body composition in the GHD group, with those individuals having the largest reductions in $\mathrm{RMR} / \mathrm{kg}$ fat free mass/day at six months having the largest increases in fat mass (fig 4) and percentage fat (fig 5) at a year $(\mathrm{p}<0.05)$. No such association was seen in the

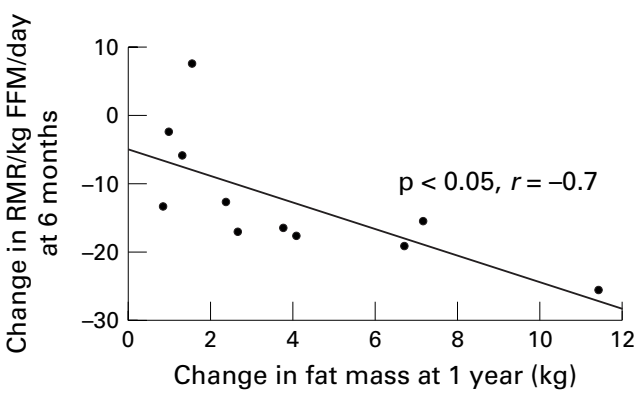

Figure 4 Change in resting metabolic rate $(R M R) / \mathrm{kg}$ fat free mass at six months after stopping treatment and subsequent change in fat mass at one year in patients with growth hormone deficiency. 


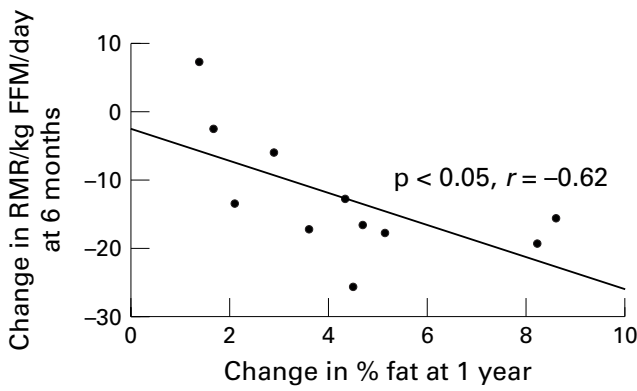

Figure 5 Change in resting metabolic rate (RMR)/kg fat free mass at six months after stopping treatment and subsequent change in percentage fat at one year in patients with growth hormone deficiency.

non-GHD group. The changes in $\mathrm{RMR} / \mathrm{kg}$ fat free mass and the subsequent changes in body composition were similar whether the patients with GHD had isolated GHD or multiple pituitary hormone deficiencies.

There were no significant relations between pretreatment $\mathrm{GH}$ concentrations on stimulation testing and the metabolic changes that followed discontinuation of $\mathrm{GH}$ treatment.

\section{BONE MINERALISATION}

There were no significant differences in $\%$ BMC when the patients with GHD were compared with the controls (mean (SD), $97.5 \%(3.9 \%)$ and $101.0 \%(5.8 \%)$, respectively) at the time of stopping treatment. However, the non-GHD group had a lower \%BMC (mean (SD) $94.7 \%(3.4 \%)$ ) than the controls $(\mathrm{p}<0.05)$. No significant changes in BMC were noted over the year of the study in either GHD group or the non-GHD group.

\section{Discussion}

Our study has shown that RMR is reduced two weeks after stopping $\mathrm{GH}$ treatment at the end of the pubertal growth spurt and remains suppressed up to one year later in individuals previously identified as having childhood onset GHD when compared with healthy controls. An increase in fat mass and percentage body fat are evident six months after stopping $\mathrm{GH}$ and these body composition changes remain one year after discontinuing treatment, although no further significant increases occur between six months and a year. This mirrors the effects seen after starting $\mathrm{GH}$ treatment in children, when maximum changes in fat free mass occurred in the first six weeks, with only small increases thereafter. ${ }^{14}$ However, an initial increase in $\mathrm{RMR} / \mathrm{kg}$ fat free mass/day values in newly treated patients after six weeks of $\mathrm{GH}$ treatment had returned to pretreatment levels by 12 weeks, ${ }^{14}$ whereas in our study, RMR values remained suppressed one year after discontinuing treatment.

It is interesting to note that while on $\mathrm{GH}$ treatment, non-GHD patients had a higher $\mathrm{RMR} / \mathrm{kg}$ fat free mass/day than the healthy controls, but a year after discontinuing therapy, values were similar. This might suggest that the non-GHD patients experienced an abnormally raised RMR while receiving $\mathrm{GH}$ treatment, perhaps as a consequence of abnormally raised serum GH concentrations. Whether this might have potentially adverse effects on future health is unknown.

We have shown important early metabolic changes on discontinuing $\mathrm{GH}$ treatment and subsequent changes in body composition. Changes in fat mass were only seen in the patients with GHD. Although percentage fat was increased in both GHD and non-GHD groups, when measured by skinfold thickness at six months, this was only sustained in the patients with GHD at one year. The control group also demonstrated an increase in fat mass at one year, although this increase was not as large as that seen in the GHD group, and no change in percentage fat was noted. The control group contained a higher proportion of girls than the GHD and non-GHD patient groups. We recruited the controls from a local school and were limited by the smaller number of boys who agreed to take part. It might be expected that the healthy control girls would experience larger increases in body fat during adolescence than boys and thus the observed difference between the patients and controls over the year after $\mathrm{GH}$ treatment is of even greater clinical importance. The changes in body composition seen in patients with GHD previously treated with GH cannot be attributed entirely to the metabolic sequelae of stopping the $\mathrm{GH}$ treatment, but may partially reflect the normal changes seen at the end of puberty. Clearly, influences other than GH affect body composition in these individuals. Our study did not attempt to assess changes in physical activity or dietary intake, either of which might affect body composition. It is interesting to note, however, that no significant changes in body composition were seen in the period of the study during which the patients remained on GH treatment (median, 9.4 months). Four patients had multiple pituitary hormone deficiencies and were on replacement treatment with other hormones (such as thyroxine, sex steroids, or hydrocortisone), which might have implications for body composition. The serum concentrations of these hormones were monitored before and during our study and remained within the relevant therapeutic ranges, suggesting that these concurrent treatments were unlikely to have influenced the results.

Whole body BMC was not significantly reduced in the patients with GHD nor were significant reductions noted one year after discontinuing GH treatment. This is in keeping with some studies in young adults, ${ }^{24}$ although others have demonstrated considerable reductions in bone mineral density in older individuals with prolonged GHD. ${ }^{5}$ Our findings suggest that adequate $\mathrm{GH}$ treatment in children prevents the development of relative osteopenia, which may be seen in adults who have experienced prolonged GHD. Longer follow up may be necessary to detect reductions in bone mineralisation after stopping $\mathrm{GH}$ treatment. Reduced BMC was demonstrated in the five non-GHD patients. Three of these had Turner's syndrome and the reduced BMC may reflect suboptimal oestrogen treatment. One 
other had Leri-Weill syndrome and the abnormal bone development in this syndrome might be expected to affect BMC measurements.

Presently, adolescent patients discontinue GH treatment when they have completed their growth. Because $\mathrm{GH}$ is now available for the treatment of GHD in adult life, there is increased interest in identifying those individuals diagnosed as having GHD in childhood who would most likely benefit from longer term treatment into adult life, once growth has been completed. At present, the licence for $\mathrm{GH}$ treatment in adult life permits treatment in adults with profound GHD $(<5 \mathrm{mU} / \mathrm{ml})$, although previous studies of the metabolic effects of $\mathrm{GH}$ treatment in adult life have shown benefits in populations with pretreatment $\mathrm{GH}$ concentrations varying between $3 \mathrm{mU} / \mathrm{ml}$ and $10 \mathrm{mU} / \mathrm{ml}^{25-27}$ It is unlikely, therefore, that an absolute concentration of $\mathrm{GH}$ could be used to determine which individuals would benefit from $\mathrm{GH}$ treatment in adult life. Given the limited correlation between biochemical measures of GH deficiency and some of the subsequent physiological effects (such as growth) of treatment, and also the poor correlation between the results of $\mathrm{GH}$ testing in earlier childhood with results obtained in young adult life, ${ }^{13}$ our results suggest that the decision for continued treatment of GHD into adult life should be based partly on evidence of physiological benefit rather than purely on the results of GH stimulation testing performed in early childhood. It is currently recommended that re-evaluation of the GH response to pituitary stimulation testing should also be included in the assessment of the need for longer term GH treatment. Unfortunately, such data are not available for most of our patients, many of whom declined further testing of $\mathrm{GH}$ secretory status at this stage.

Other studies have investigated the effect of discontinuing $\mathrm{GH}$ treatment. Increases in fat mass have been demonstrated by bioelectrical impedance measurements in individuals with continuing severe GHD, when measured three months after discontinuing $\mathrm{GH}$, whereas no change was noted in patients without GHD. ${ }^{28}$ Percentage body fat measured by DXA scanning has also been shown to be increased at six and 12 months after discontinuing GH but in this particular study the control group showed no such increases. ${ }^{29}$ Small and variable reductions in muscle strength and size have been shown to occur one year after discontinuing $\mathrm{GH}$ treatment in a small group of adolescents, but changes in the normal population at this age are not well documented, making it difficult to interpret this finding. ${ }^{30}$

However, to our knowledge, our study is the first to demonstrate that abnormalities of RMR can be measured within a short time interval of discontinuing $\mathrm{GH}$ treatment. One of the aims of our study was to evaluate whether the early metabolic effects of discontinuing $\mathrm{GH}$ might be predictive of longer term adverse effects on body composition and whether these effects could be used to identify those individuals most likely to benefit from treatment with $\mathrm{GH}$ in early adult life. We have demonstrated that those individuals experiencing the greatest reduction in $\mathrm{RMR} / \mathrm{kg}$ fat free mass subsequently show the largest increases in body fat, although the reduction in RMR does not explain all of the changes in body fat $\left(R^{2}\right.$ $=0.49$; fig 4 ), given that some increase in body fat may be expected in normal healthy adolescents of this age. We would suggest that measuring early changes in RMR on discontinuing $\mathrm{GH}$ treatment could be used to identify those individuals who would benefit from continuation of GH treatment into adult life. In units where the necessary equipment is unavailable, measurement of skinfold thicknesses to determine changes in body composition during the year after stopping $\mathrm{GH}$ could be used to identify those individuals with large increases in body fat who should be encouraged to undergo repeat assessment of GH secretory reserve. GH treatment may then be reintroduced at an early stage in those with confirmed GHD to prevent further adverse effects on body composition.

We are grateful to $\mathrm{Mr} \mathrm{JH}$ Pearce, $\mathrm{Mr} \mathrm{D}$ Coleman, and Mrs RJ Pettit for assistance with the DXA measurements; Professor A Aynsley-Green and Dr PJ Smith for advice on study design and for allowing us to study their patients; and Pharmacia-Upjohn for financial support for the study.

1 Rosen T, Bosaeus I, Tolli J, Lindstedt G, Bengtsson B-A. Increased body fat mass and decreased extracellular fluid volume in adults with growth hormone deficiency. Clin volume in adults with growth
Endocrinol (Oxf) 1993;38:63-71.

2 de Boer H, Blok GJ, Voerman HJ, Phillips M, Schouten JA. Serum lipid levels in growth hormone deficient men. Metabolism: Clinical and Experimental 1994;43:199-203.

3 Juul A, Jorgensen JO, Christiansen JS, Muller J, Skakkeboek NE. Metabolic effects of growth hormone: a rationale for continued growth hormone treatment of growth hormone deficient adults after cessation of linear growth. Horm Res 1995;44(suppl 3):64-72.

4 Cuneo RC, Salomon F, McGauley GA, Sonksen PH. The growth hormone deficiency syndrome in adults. Clin Endocrinol(Oxf) 1992;37:387-97.

5 Beshyah SA, Freemantle C, Thomas E, et al. Abnormal body composition and reduced bone mass in growth hormone deficient hypopituitary adults. Clin Endocrinol 1995;42:179-89.

6 Rosen T, Johannsson G, Johansson J-O, Bengtsson B-A. Consequences of growth hormone deficiency in adults and Consequences of growth hormone deficiency in adults and
the benefits and risks of recombinant human growth hormone treatment. Horm Res 1995;43:93-9.

7 Henneman DH, Henneman PH. Effects of human growth hormone on levels of blood and urinary carbohydrate and fat metabolites in man. $\mathcal{F}$ Clin Invest 1960;39:121-30.

8 Gregory JW, Greene SA, Jung RT, Scrimgeour CM, Rennie MJ. Changes in body composition and energy expenditure after six weeks' growth hormone treatment. Arch Dis Child 1991;66:598-602.

9 Beshyah SA, Freemantle C, Shahi M, et al. Replacement treatment with biosynthetic human growth hormone in growth hormone deficient hypopituitary adults. Clin Endocrinol (Oxf) 1995;42:73-84.

10 Lonn L, Johansson G, Sjostrom L, Kvist H, Oden A, Bengtsson BA. Body composition and tissue distributions in growth hormone deficient adults before and after growth hormone treatment. Obes Res 1996;4:45-54.

11 Hansen TB, Vahl N, Jorgensen JO, Christiansen JS, Hagen C. Whole body and regional soft tissue changes in growth hormone deficient adults after one year of growth hormone hormone deficient adults after one year of growth hormone treatment: a double-blind, randomised, place

12 McGauley GA, Cuneo RC, Salomon F, Sonksen PH. Growth hormone deficiency and quality of life. Horm Res 1996;45:34-7.

13 Nicolson A, Toogood AA, Rahim A, Shalet SM. The prevalence of severe growth hormone deficiency in adults who received growth hormone replacement in childhood. Clin Endocrinol (Oxf) 1996;44:311-16.

14 Gregory JW, Greene SA, Jung RT, Scrimgeour CM, Rennie MJ. Metabolic effects of growth hormone treatment: an early predictor of growth response? Arch Dis Child 1993;68: 205-9.

15 Freeman JV, Cole TJ, Chinn S, Jones PRM, White EM, Preece MA. Cross sectional stature and weight reference curves for the UK, 1990. Arch Dis Child 1995;73:17-24.

16 Cole TJ, Freeman JV, Preece MA. Body mass index Cole TJ, Freeman JV, Preece MA. Body mass index
reference curves for the UK, 1990. Arch Dis Child 1995;73: 25-9.

17 Tanner JM. Growth at adolescence. 2nd ed. Oxford: Blackwell, 1962 
18 Weir JBdeV. New methods for calculating metabolic rate with special reference to protein metabolism. I Physiol
(Lond) $1949 ; 109: 1-9$.

19 Durnin JVGA, Rahaman MM. The assessment of the amount of fat in the human body from measurements of skinfold thickness. Br F Nutr 1967;21:681-9.

20 Siri WE. Body composition from fluid spaces and density : analysis of methods. In: Brozek J, Henschel A, eds. Techniques for measuring body composition. Washington DC National Academy of Science, 1961:223-44.

21 Svendsen OL, Haarbo J, Christiansen C. Accuracy of measurements of body composition by dual energy x-ray absorptiometry in vivo. Am F Clin Nutr 1993;57:605-8.

22 Warner JT, Cowan FJ, Dunstan FDJ, Evans WD, Webb DKH, Gregory JW. Measured and predicted bone mineral content in healthy boys and girls aged 6 to 18 years: adjustment for body size and puberty. Acta Paediatr 1998;87: 244-9.

23 Bland JM, Altman DG. Statistical methods for assessing the agreement between two methods of clinical measurements. agreement between two methods of clinical measurements.

24 Lancet 1986,1:307-10.

de Boer $\mathrm{H}$, van der Veen EA. Why retest young adults with
childhood onset growth hormone deficiency? $\mathcal{f}$ Clin Endocrinol Metab 1997;82:2032-6.
25 Salomon F, Cuneo RC, Hesp R, Sönksen PH. The effects of treatment with recombinant human growth hormone on body composition and metabolism in adults with growth hormone deficiency. $N$ Engl f Med 1989;321:1797-803. 26 Jørgensen JOL, Pedersen SA, Thuesen L, et al. Beneficial
effects of growth hormone treatment in GH-deficient adults. Lancet 1989;i:1221-5.

27 Whitehead HM, Boreham C, et al. Growth hormone treatment of adults with growth hormone deficiency: results of a 13-month placebo controlled cross-over study. Clin Endocrinol (Oxf) 1992;36:45-52.

28 Colle M, Auzerie J. Discontinuation of growth hormone therapy in growth-hormone-deficient patients: assessment of body fat mass using bioelectrical impedance. Horm Res 1993;39:192-6.

29 Ogle GD, Moore B, Lu PW, Craighead A, Briody JN, Cowell CT. Changes in body composition and bone density after discontinuation of growth hormone in adolescence: an interim report. Acta Paediatr Suppl 1994;399:3-7.

30 Rutherford OM, Jones DA, Round JM, Preece MA. Changes in skeletal muscle after discontinuation of growth hormone treatment in young adults with hypopituitarism. Acta Paediatr Scand Suppl 1989;356:61-3. 